\title{
Breve panorama sobre el sector de telecomunicaciones de India
}

Amarendra Khatua ${ }^{1}$

Es ampliamente reconocido que la industria de la telecomunicación de India ha acelerado el desarrollo socio económico del país. Con una cantidad increíble de conexiones que ascendía a 964 millones en noviembre de 2014, la red de telecomunicaciones de India es en la actualidad el segundo mayor mercado de telecomunicaciones del mundo y la última década ha registrado un crecimiento extraordinario.

Al comprender el potencial que tiene esta industria en el desarrollo del potencial económico de India, el gobierno ha sido proactivo en sus esfuerzos para transformar el país en un centro mundial de telecomunicaciones: políticas liberales que facilitan el acceso a los mercados para equipos tecnológicos y marcos reguladores justos para ofrecer servicios de telecomunicaciones a precios asequibles. La desregulación de las normas de inversión extranjera directa ha hecho que el sector sea uno de los de mayor crecimiento y uno de los cinco principales generadores de oportunidades de empleo en el país. La política nacional de telecomunicaciones de 2012, propone un sistema de licencias unificado, la completa portabilidad numérica de teléfonos móviles y roaming gratuito.

En particular, el año 2014 ha marcado el ritmo para la industria con la tan esperada y exitosa licitación del espectro $2 \mathrm{G}$ que generó ingresos para el sector. Luego de superado el escándalo del espectro 2G, la industria de telecomunicaciones de India se ha erigido como un fénix con un aumento en el alcance y la eficacia.

Es por ello dable revisar brevemente el panorama sobre la dimensión y naturaleza del mercado así como su marco regulatorio y el escenario actual de la industria de telecomunicaciones de India.

\section{Dimensión y mercado}

India es el segundo mayor mercado mundial de telecomunicaciones con 964 millones de clientes a noviembre de 2014. Con 164,81 millones, India fue el tercer país en importancia en el número de suscriptores a Internet en 2013. Este número ha crecido a una tasa de crecimiento anual compuesta (por sus siglas en inglés CAGR) de 52\%, pasando de 8,6 millones en 2006 a 243 millones en 2014.

El segmento de telefonía inalámbrica ( $97 \%$ del total de suscripciones telefónicas) domina el mercado, mientras que el de línea fija ocupa el resto. Durante los años financieros 2007 y 2014, las suscripciones

\footnotetext{
${ }^{1}$ Embajador de la India en la Argentina (Concurrente en Paraguay y Uruguay), desde julio de 2012. Sus destinos anteriores fueron Madrid, Ciudad de México, Karachi, Moscú y Nueva York. Ha ocupado también otros cargos oficiales y ha sido Embajador en Etiopia, entre 2005 y 2007 y Enviado Especial de la India a Sudan y Sudán del Sur, desde octubre de 2010 hasta julio de 2012. Es también un prolífico autor literario, con publicaciones en Odia, Hindi e inglés, traducidos a su vez a Odia, Inglés, Castellano y la mayoría de las lenguas indias, desde 1972.
} 
móviles crecieron a una CAGR del 27,5\% a 904,5 millones. Se estima que la penetración de las telecomunicaciones en el mercado nacional rural crecerá de un 41\% en marzo de 2013 a un 70\% hacia 2017. Es de esperar que el aumento del número de teléfonos inteligentes, junto con una mejora en la seguridad móvil, estimulen el crecimiento de las transacciones por telefonía, dado que ya en 2014 se triplicó su valor respecto del año anterior. Además, se espera que la industria de los servicios móviles de valor agregado (en inglés MVAS) se expanda a una CAGR de 30,9\% de US\$1100 millones en 2007 a US\$ 9500 millones hacia 2015. La densidad telefónica en India alcanzó un impresionante 75,2 en el año financiero 2014, pasando de un 18,3 en 2007, una estadística que genera incredulidad (India Brand Equity Foundation 2015a , 2015b).

Los ingresos por telefonía inalámbrica y de línea fija alcanzaron en el año financiero 2013 casi US\$40 mil millones, siendo Bharti Airtel la empresa líder, al poseer el 23\% del mercado de telefonía móvil, seguido por Vodafone con el 19\%. Los suscriptores inalámbricos representan casi el $97 \%$ del mercado (57\% urbano, 40\% rural), el resto es captado por el segmento de telefonía fija.

Se espera que el sector de telecomunicaciones de India genere cuatro millones de puestos de trabajo de manera directa e indirecta en los próximos cinco años, a partir de los esfuerzos gubernamentales para incrementar su uso en zonas rurales, el crecimiento de la cantidad de teléfonos inteligentes y el uso de internet.

\section{Marco regulatorio}

La industria de telecomunicaciones en India es regulada por una autoridad regulatoria independiente (en inglés Telecom Regulatory Authority of India - TRAI), dirigido por una Secretaría (actualmente a cargo del Sr. Rahul Khullar). El secretario es asistido por consejeros en diversas cuestiones tal como Redes Móviles, Redes de Interconectividad y Fijas, Banda Ancha y Análisis de Políticas, Calidad del Servicio, Servicios de Difusión y por Cable, etc. Uno de los objetivos centrales de TRAl es proporcionar un ambiente de políticas transparentes y justas que promueva la igualdad de condiciones y facilite la competencia justa.

La industria de telecomunicaciones india ha tenido su cuota de problemas en relación a la estafa en las licitaciones del espectro 2G. Sin embargo, las licencias adjudicadas han sido canceladas en su totalidad y bajo el nuevo gobierno el proceso es ágil y transparente. Este renacimiento ha creado un ambiente positivo que nutre la sana competencia en la industria y una distribución exitosa del espectro 2 G en 2014 y 2015, alcanzando ingresos récord para el erario público. 


\section{Inversiones y oportunidades}

Con emocionantes oportunidades apareciendo cada día, el sector ha tenido muchas inversiones y desarrollos. La industria atrajo inversión extranjera directa por un valor de US\$16.994,68 millones entre abril de 2000 y enero de 2015, de acuerdo con la información publicada por el Departamento de Políticas y Promoción Industrial (en inglés DIPP). El Gobierno de la India planea lanzar wifi de alta velocidad gratis en 2.500 ciudades y pueblos del país en los próximos tres años y el programa, que incluye inversiones de hasta 70 mil millones de Rupias (US\$1.120 millones), será implementado por Baharat Sancar Nigam Ltd (BSNL), propiedad del Estado.

Se espera que los ciudadanos de India reciban wifi gratis por un mínimo de 2 megabits por segundo (en inglés MBPS) en cada uno de los puntos de servicio del gobierno tal como estaciones ferroviarias, aeropuertos, paradas de autobuses, hospitales y todos los departamentos del gobierno que atienden al público de manera habitual. Las oportunidades para el desarrollo de productos innovadores e iniciativas de telecomunicaciones centradas en los ciudadanos hacen que sea uno de los sectores más interesantes para proyectos de alianzas público-privadas (Government of India, Ministry of Communications and Information Technology, 2015; India Brand Equity Foundation 2015a, 2015b).

\section{El camino por delante}

India emergerá como uno de los actores principales en el mundo virtual al poseer 700 millones de usuarios de internet de los 4.700 millones existentes a nivel mundial hacia 2025. Con políticas regulatorias favorables por parte del gobierno y los servicios $4 G$ en el mercado, se espera un rápido crecimiento en el sector de telecomunicaciones durante los próximos años. Además, con estas mejoras, es de esperar que servicios tales como seguridad y vigilancia, monitoreo remoto de cajeros automáticos, automatización de los hogares, gestión del tráfico, venta minorista, logística y red eléctrica realicen sinergias para su mutuo beneficio y crecimiento.

En síntesis, se puede afirmar con total seguridad que la industria de las telecomunicaciones de India ofrece oportunidades increíbles para las próximas décadas. Con una población de 1500 millones, el tamaño del país y su poder adquisitivo, brinda infinitas oportunidades para la inversión y la innovación en negocios a una escala significativa que, de aprovecharse correctamente, puede catapultar la economía india incluso más. Este sector, es un multiplicador de fuerza; sin dudas es el sector más excitante de la economía del país y lo seguirá siendo durante las próximas décadas. 


\section{Referencias}

Government of India, Ministry of Communicationas and Information Technology (2015). One Year of Activities and Achievements. New Delhi: Ministry of Communicationas and Information Technology, Government of India. Recuperado de http://www.dot.gov.in/sites/default/files/rs/Square\%20Book.pdf

India Brand Equity Foundation (2015a). Telecom Sector in India. Recuperado de http://www.ibef.org/industry/telecommunications.aspx

India Brand Equity Foundation (2015b). Telecommunication. New Delhi: india Brand Equity Foundation. Recuperado de http://www.ibef.org/download/Telecom-August-2015.pdf 